\title{
The Difference Between Set and Delivered Tidal Volume: A Lung Simulation Study
}

This article was published in the following Dove Press journal:

Medical Devices: Evidence and Research

\author{
Yoshikazu Yamaguchi (iD ${ }^{1-3}$ \\ Tetsuya Miyashita' \\ Yuko Matsuda' \\ Makoto Sasaki ${ }^{\prime}$ \\ Shunsuke Takaki (D) \\ Stephani S Kim (iD) ${ }^{2}$ \\ Joseph D Tobias $\mathbb{D}^{2,3}$ \\ Takahisa Goto (D) \\ 'Department of Anesthesiology and \\ Critical Care, Yokohama City University, \\ Kanagawa, Japan; ${ }^{2}$ Department of \\ Anesthesiology and Pain Medicine, \\ Nationwide Children's Hospital, \\ Columbus, OH, USA; ${ }^{3}$ Department of \\ Anesthesiology and Pain Medicine, The \\ Ohio State University Wexner Medical \\ Center, Columbus, OH, USA
}

Background: Precise control of tidal volume is one of the keys in limiting ventilatorinduced lung injury and ensuring adequate ventilation in mechanically ventilated neonates. The aim of the study was to compare the tidal volume (mVT) measured from the expiratory limb of the ventilator with the actual tidal volume (aVT) that would be delivered to the patient using a lung model to simulate a neonate.

Methods: This study was conducted using the ASL5000 lung simulator. Three combinations of parameters were set: resistance $\left(\mathrm{cmH}_{2} \mathrm{O} / \mathrm{L} / \mathrm{sec}\right)$ and compliance $\left(\mathrm{mL} / \mathrm{cmH}_{2} \mathrm{O}\right)$ of 50 and 2 (Group 1), 100 and 1 (Group 2), and 150 and 0.5 (Group 3), respectively. The ASL5000 was connected to each of the ventilators including one anesthesia machine ventilator (Drager Fabius GS) and two ICU ventilators (Servo-i Universal and Evita Infinity V500). Each ventilator was evaluated with a set tidal volume of $30 \mathrm{~mL}(\mathrm{sVT})$ and a respiratory rate of 25 breathes/minute in both the volume-controlled ventilation (VCV) and dual-controlled ventilation (DCV) modes.

Results: The discrepancies between sVT, mVT and aVT were highest with the Fabius anesthesia machine ventilator and increased in the simulated lung injury groups. When comparing the ICU ventilators, the difference was greater the Servo-i and increased when using the DCV mode and with simulated lung injury.

Conclusion: Accurate tidal volumes were achieved only with the Infinity ICU ventilator. This was true regardless of mode of ventilation and even during simulated lung injury.

Keywords: mechanical ventilation, pediatric anesthesia, tidal volume, flow sensor, lung protective ventilation, volutrauma

\section{Introduction}

Precise control of tidal volume is one of the keys in limiting ventilator-induced lung injury (VILI), ensuring adequate ventilation, and improving outcomes in mechanically ventilated neonates. ${ }^{1}$ Tidal volume (VT) is usually measured by a sensor placed at the expiratory valve or within the expiratory limb of the ventilator. Discrepancies between the set and actual delivered tidal volume can result from various factors including circuit compression volume and the impact of fresh gas flow. Specific computer software has been developed to allow the ventilator to compensate for the volume loss within the circuit. The efficacy of such software has been previously demonstrated with tidal volumes as low as $100 \mathrm{~mL}{ }^{2}$

Modern-day ventilators on the anesthesia machine have volume-controlled ventilation (VCV), pressure-controlled ventilation (PCV), and dual-controlled ventilation (DCV). DCV is an auto-regulated mode of pressure-controlled ventilation that achieves a set tidal volume. DCV is also referred to as volume-targeted
Correspondence: Yoshikazu Yamaguchi Medicine, Nationwide Children's Hospital, Columbus, $\mathrm{OH} 43205$, USA

$\mathrm{Tel}+\mathrm{I}(6 \mid 4) 722-4200$

$\mathrm{Fax}+\mathrm{I}(6 \mathrm{I})$ 722-4203

Email yoshikaz@rd6.so-net.ne.jp 
ventilation, pressure-regulated volume-controlled ventilation (PRVC), and pressure-controlled ventilation with volume guarantee (PCV-VG). PCV has been the mainstay of mechanical ventilation in neonates because of concerns of inaccurate tidal volume related to fresh gas flow, circuit compression volume, circuit compression volume, and changing resistance and compliance. These factors may be magnified with the variable leak when an uncuffed ETT is used. However, now that cuffed ETTs have become more common in clinical care, it may be feasible to use VCV and DCV in neonates. ${ }^{1}$ The aim of this study was to compare the set tidal volume (sVT) with the tidal volume measured by the ventilator (mVT), and the actual tidal volume (aVT) measured using a lung model to simulate neonatal anesthesia care.

\section{Methods}

This study was performed in Yokohama City University Hospital. This lung simulation study was conducted using the Active Servo Lung 5000 (ASL 5000) (version 3.4, 3.5; IngMar Medical, Pittsburg, PA). The ASL 5000 is a lung analogue, which can simulate various lung parameters (resistance and compliance) and precisely measure tidal volume. One anesthesia machine ventilator, Drager Fabius GS (Drager, Germany), and ICU ventilators including the Servo-i Universal ${ }^{\mathrm{TM}}$ version 3.0.1 (Maquet, Danvers, MA) and the Evita Infinity V500 (Drager, Lubeck, Germany) were evaluated. The ASL 5000 was connected to a computer to analyze respiratory parameters and record tidal volumes. Capnometer, heat moist exchanger, and humidifier were not connected to the circuit. The lung simulator was used to simulate a 3 kilogram term neonate with and without lung involvement. Three lung models were set: resistance $(\mathrm{cmH} 2 \mathrm{O} / \mathrm{L} / \mathrm{sec})$ and compliance $(\mathrm{mL} / \mathrm{cmH} 2 \mathrm{O})$ of 50 , 2 (Group 1); 100, 1 (Group 2); and 150, 0.5 (Group 3) respectively, shown in Table $1 .^{3}$ After the standard initial machine check with a standard pediatric circuit, the ventilator was connected to the ASL 5000. Set tidal volume (sVT) was $30 \mathrm{~mL}$ during all phases of the study. Each ventilator was evaluated using a respiratory rate of 25 breaths/minute, positive end-expiratory pressure (PEEP) $3 \mathrm{cmH} 2 \mathrm{O}$, and an inspiratory time of 0.6 seconds in both the VCV and DCV modes. Ventilator displayed tidal volume hereafter referred to as measured tidal volume (mVT) was measured by the flow sensor in the expiratory limb of the ventilators. The tidal volume that was actually delivered to simulated neonatal patient (aVT) was measured by the syringe in ASL 5000 (Figure 1).
Table I Lung Simulator Settings

\begin{tabular}{|l|l|l|}
\hline Group & $\begin{array}{l}\text { Resistance }\left(\mathbf{c m H}_{\mathbf{2}}\right. \\
\text { O/L/sec) }\end{array}$ & $\begin{array}{l}\text { Compliance }\left(\mathbf{m L} / \mathbf{c m H}_{\mathbf{2}}\right. \\
\mathbf{O})\end{array}$ \\
\hline $\mathrm{I}$ & 50 & 2 \\
2 & 100 & $\mathrm{I}$ \\
3 & 150 & 0.5 \\
\hline
\end{tabular}

The aVT and the mVT were recorded in each setting for seven breaths. Statistical analysis was performed using JMP Pro ver. 13.0 (SAS, USA). $t$-test was used to compare aVT, sVT, and mVT within each group. Tukey-Kramer test was used to compare the difference between the aVT and $\mathrm{mVT}$ as well as the difference between the sVT and $\mathrm{aVT}$ of the various ventilators in each setting. Results are listed as mean \pm standard deviation.

\section{Results}

Ventilator measured tidal volume (mVT) and actual delivered VT (aVT) tidal volume measured by lung mode in the 3 lung settings and two modes of ventilation are shown in Tables 2-4 and Figure 2. Clinically significant differences were noted between the sVT, mVT, and aVT when using the Fabius anesthesia machine ventilator. These differences were as high as $40-50 \%$ in the simulated injured lung model. Likewise, there were differences when using the Servo-i ICU ventilator, but the discrepancy was less $(10 \%)$ in the VCV mode without simulated lung injury. When using the Servo-I ICU ventilator, the difference increased in the DCV mode compared to the VCV mode and also in the simulated injured lung model. The greatest agreement in sVT, mVT, and aVT set was noted with the Infinity ICU ventilator regardless of mode of ventilation and severity of simulated lung injury.

\section{Discussion}

The accurate delivery of tidal volume is essential when ventilating neonates in both the ICU and during the intraoperative period. Inaccuracies in the delivery of tidal volume may result in low minute ventilation and hypercarbia or excessive tidal volumes leading to barotrauma and lung injury. These issues may be magnified with smaller tidal volumes such as those used in neonates and in the presence of acute lung injury with changes in pulmonary resistance and compliance. Furthermore, given variations in the technology and computer software, clinically significant differences may exist between the currently available ventilators. Our study revealed that 


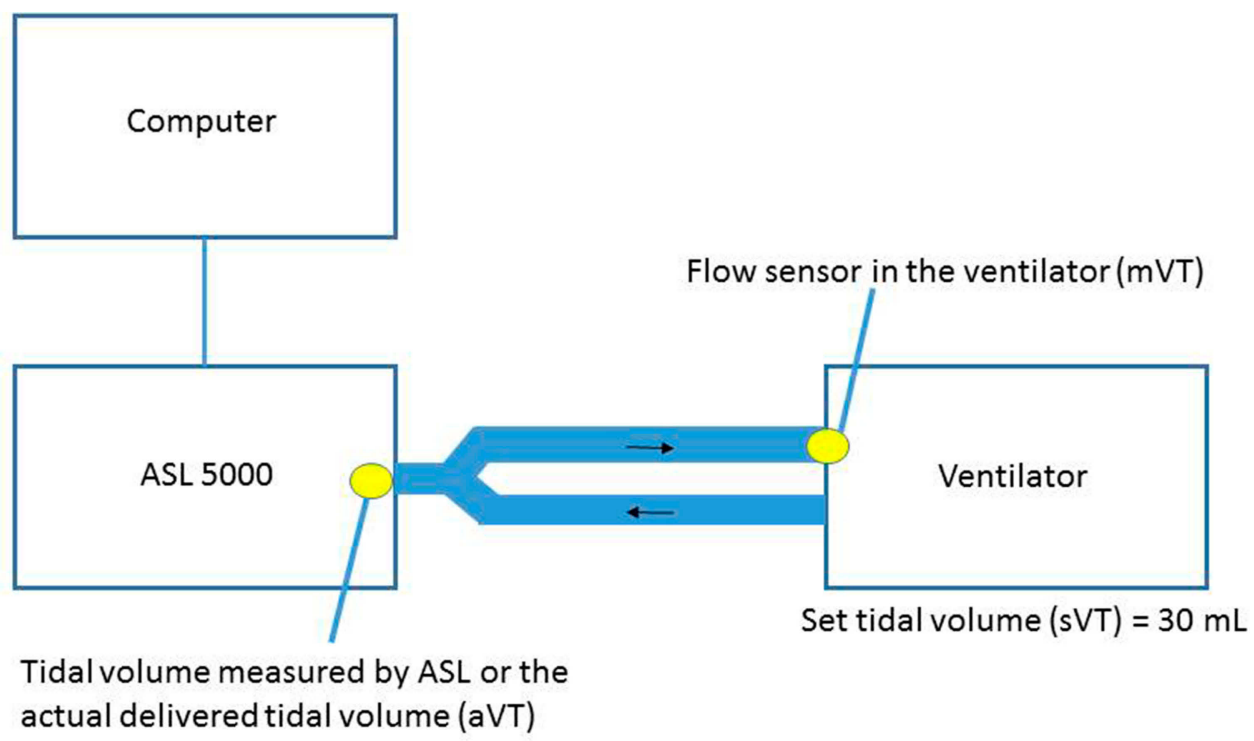

Figure I Diagram of the set-up for this study. The ASL 5000 was connected to the computer which recorded the data. Ventilators were connected to ASL 5000 using a standard pediatric circuit. Set tidal volume (sVT) was $30 \mathrm{~mL}$. Actually delivered tidal volume (aVT) was measured by the syringe in ASL5000. Ventilator displayed tidal volume $(\mathrm{mVT})$ was measured by the flow sensor in expiratory limb of the ventilator. $\mathrm{aVT}=$ delivered tidal volume measured by the ASL 5000 lung model; $\mathrm{mVT}=$ ventilator displayed or measured tidal volume; $\mathrm{sVT}=$ ventilator set tidal volume of $30 \mathrm{~mL}$.

there were clinically significant differences between sVT, mVT and aVT based on the severity of the simulated lung injury, the type of ventilator in use, as well as the mode of ventilation (VCV vs DCV).

Many factors may lead to the dissociation between these parameters including volume loss when an uncuffed ETT is in use, circuit compression volume, and fresh gas flow. The majority of previous studies have reported that mVT overestimates aVT because of volume loss due to circuit compression. ${ }^{4-6}$ Heulitt et al studied 68 infants and children to compare mVT using the Servo-i with aVT measured by a pneumotachometer placed between the Y-piece of the ventilator and the ETT. ${ }^{7}$ They reported that $\mathrm{mVT}$ without circuit compensation, generally overestimated aVT; however, with circuit compensation, mVT underestimated aVT as noted in our study. Of note, the discrepancy would be magnified in smaller patients as the difference between aVT and mVT was $\pm 30 \mathrm{~mL}$ regardless of the patient's body weight.

Bachillar et al compared mVT and aVT, using the Avance, Aisys anesthesia machine (GE Healthcare, Madison, WI) and the Apollo anesthesia machine (Drager Medical, Telford, PA) with aVT measured by a pneumotachometer placed between the Y-piece of the circuit and the ETT. ${ }^{2}$ They found that modern anesthesia machines with compliance compensation delivered an aVT with an error of $<9 \%$. The differing results from the current study likely are the result of the use of different ventilators. Other potential factors affecting the results may have been the smaller set tidal volume in the current study as well as the use of a simulated injured lung with a higher airway resistance and lower compliance. These

Table 2 Ventilator Displayed or Measured Tidal Volume and Actually Delivered Tidal Volume

\begin{tabular}{|l|l|l|l|l|l|l|l|l|l|}
\hline & \multicolumn{3}{|l}{ Group I } & \multicolumn{2}{l|}{ Group 2 } & \multicolumn{2}{l|}{ Group 3 } \\
\cline { 2 - 9 } & aVT & mVT & P value & aVT & mVT & P value & aVT & mVT & P value \\
\hline Fabius GS VCV & $26.6 \pm 0.56$ & $23.0 \pm 0.58$ & $<0.001$ & $26.7 \pm 0.18$ & $15.6 \pm 0.9$ & $<0.001$ & $25.7 \pm 0.49$ & $17.6 \pm 3.9$ & $<0.001$ \\
Servo-I, VCV & $31.4 \pm 0.12$ & $29.4 \pm 0.53$ & $<0.001$ & $30.1 \pm 0.13$ & $27.7 \pm 0.49$ & $<0.001$ & $29.2 \pm 0.26$ & $26 \pm 0.0$ & $<0.001$ \\
Servo-I, DCV & $30.1 \pm 0.17$ & $26.6 \pm 0.53$ & $<0.001$ & $28.9 \pm 0.24$ & $24.9 \pm 0.38$ & $<0.001$ & $27.4 \pm 0.14$ & $23.5 \pm 0.55$ & $<0.001$ \\
Infinity V500, VCV & $30.2 \pm 0.13$ & $29.9 \pm 0.9$ & 0.28 & $30.1 \pm 0.12$ & $30.0 \pm 0.0$ & 0.04 & $28.9 \pm 0.08$ & $30.0 \pm 0$ & $<0.001$ \\
Infinity V500, DCV & $30.6 \pm 0.13$ & $30.0 \pm 0.0$ & $<0.001$ & $30.9 \pm 0.18$ & $30.0 \pm 0.0$ & $<0.001$ & $30.6 \pm 0.07$ & $30.0 \pm 0.0$ & $<0.001$ \\
\hline
\end{tabular}

Notes: For all studies, the set tidal volume was $30 \mathrm{~mL}$. aVT = actual delivered tidal volume measured by the ASL 5000 lung model; $\mathrm{mVT}=$ ventilator displayed or measured tidal volume.

Abbreviations: DCV, dual-controlled ventilation; VCV, volume-controlled ventilation. 
Table 3 Difference Between Actual Delivered Tidal Volume (aVT) and Measured Tidal Volume (mVT)

\begin{tabular}{|c|c|c|c|c|c|c|c|}
\hline Ventilator & Group & Mean \pm SD $(\mathrm{mL})$ & Fabius GS VCV & $\begin{array}{l}\text { Servo-I } \\
\text { VCV }\end{array}$ & $\begin{array}{l}\text { Servo-I } \\
\text { DCV }\end{array}$ & $\begin{array}{l}\text { Infinity } \\
\text { VCV }\end{array}$ & $\begin{array}{l}\text { Infinity } \\
\text { DCV }\end{array}$ \\
\hline $\begin{array}{l}\text { Fabius GS } \\
\text { VCV }\end{array}$ & $\begin{array}{l}\text { Group I } \\
\text { Group } 2 \\
\text { Group } 3\end{array}$ & $\begin{array}{l}3.6 \pm 0.89 \\
10.2 \pm 0.92 \\
8.1 \pm 4.1\end{array}$ & & & & & \\
\hline $\begin{array}{l}\text { Servo-i } \\
\text { VCV }\end{array}$ & $\begin{array}{l}\text { Group I } \\
\text { Group } 2 \\
\text { Group } 3\end{array}$ & $\begin{array}{l}2.0 \pm 0.55 \\
2.4 \pm 0.44 \\
3.2 \pm 0.23\end{array}$ & $\begin{array}{l}<0.001 \\
<0.001 \\
<0.001\end{array}$ & & & & \\
\hline $\begin{array}{l}\text { Servo-i } \\
\text { DCV }\end{array}$ & $\begin{array}{l}\text { Group I } \\
\text { Group } 2 \\
\text { Group } 3\end{array}$ & $\begin{array}{l}3.6 \pm 0.61 \\
4.1 \pm 0.43 \\
3.8 \pm 0.61\end{array}$ & $\begin{array}{l}1.00 \\
<0.001 \\
0.0034\end{array}$ & $\begin{array}{l}<0.001 \\
<0.001 \\
0.9762\end{array}$ & & & \\
\hline $\begin{array}{l}\text { Infinity } \\
\text { VCV }\end{array}$ & $\begin{array}{l}\text { Group I } \\
\text { Group } 2 \\
\text { Group } 3\end{array}$ & $\begin{array}{l}0.38 \pm 0.86 \\
0.1 \pm 0.11 \\
-1.1 \pm 0.08\end{array}$ & $\begin{array}{l}<0.001 \\
<0.001 \\
<0.001\end{array}$ & $\begin{array}{l}0.001 \\
<0.001 \\
0.0018\end{array}$ & $\begin{array}{l}<0.001 \\
<0.001 \\
<0.001\end{array}$ & & \\
\hline $\begin{array}{l}\text { Infinity } \\
\text { DCV }\end{array}$ & $\begin{array}{l}\text { Group I } \\
\text { Group } 2 \\
\text { Group } 3\end{array}$ & $\begin{array}{l}0.59 \pm 0.14 \\
0.90 \pm 0.18 \\
0.61 \pm 0.07\end{array}$ & $\begin{array}{l}<0.001 \\
<0.001 \\
<0.001\end{array}$ & $\begin{array}{l}0.0043 \\
<0.001 \\
0.105\end{array}$ & $\begin{array}{l}<0.001 \\
<0.001 \\
0.0364\end{array}$ & $\begin{array}{l}0.98 \\
<0.0427 \\
<04612\end{array}$ & \\
\hline
\end{tabular}

Notes: For all studies, the set tidal volume was $30 \mathrm{~mL}$. aVT = delivered tidal volume measured by the ASL 5000 lung model; $\mathrm{mVT}=$ ventilator displayed or measured tidal volume. Abbreviations: DCV, dual-controlled ventilation; VCV, volume-controlled ventilation.

Table 4 Difference Between Actual Delivered Tidal Volume (aVT) and Set Tidal Volume in Each Setting (sVT)

\begin{tabular}{|c|c|c|c|c|c|c|c|}
\hline Ventilator & Group & Mean $\pm S D(m L)$ & $\begin{array}{l}\text { Fabius GS } \\
\text { VCV }\end{array}$ & $\begin{array}{l}\text { Servo-I } \\
\text { VCV }\end{array}$ & $\begin{array}{l}\text { Servo-I } \\
\text { DCV }\end{array}$ & $\begin{array}{l}\text { Infinity } \\
\text { VCV }\end{array}$ & $\begin{array}{l}\text { Infinity } \\
\text { DCV }\end{array}$ \\
\hline Fabius GS, VCV & $\begin{array}{l}\text { Group I } \\
\text { Group } 2 \\
\text { Group } 3\end{array}$ & $\begin{array}{l}-3.4 \pm 0.56 \\
-3.9 \pm 0.18 \\
-4.3 \pm 0.49\end{array}$ & & & & & \\
\hline Servo-i,VCV & $\begin{array}{l}\text { Group I } \\
\text { Group } 2 \\
\text { Group } 3\end{array}$ & $\begin{array}{l}1.4 \pm 0.12 \\
0.14 \pm 0.13 \\
-0.77 \pm 0.26\end{array}$ & $\begin{array}{l}<0.001 \\
<0.001 \\
<0.001\end{array}$ & & & & \\
\hline Servo-i,DCV & $\begin{array}{l}\text { Group I } \\
\text { Group } 2 \\
\text { Group } 3\end{array}$ & $\begin{array}{l}0.14 \pm 0.17 \\
-1.1 \pm 0.24 \\
-2.7 \pm 0.14\end{array}$ & $\begin{array}{l}<0.001 \\
<0.001 \\
<0.001\end{array}$ & $\begin{array}{l}<0.001 \\
<0.001 \\
<0.001\end{array}$ & & & \\
\hline $\begin{array}{l}\text { Infinity } \\
\text { VCV }\end{array}$ & $\begin{array}{l}\text { Group I } \\
\text { Group } 2 \\
\text { Group } 3\end{array}$ & $\begin{array}{l}0.24 \pm 0.13 \\
0.1 \pm 0.12 \\
-1.1 \pm 0.08\end{array}$ & $\begin{array}{l}<0.001 \\
<0.001 \\
<0.001\end{array}$ & $\begin{array}{l}<0.001 \\
0.99 \\
0.16\end{array}$ & $\begin{array}{l}0.96 \\
<0.001 \\
<0.001\end{array}$ & & \\
\hline $\begin{array}{l}\text { Infinity } \\
\text { DCV }\end{array}$ & $\begin{array}{l}\text { Group } 1 \\
\text { Group } 2 \\
\text { Group } 3\end{array}$ & $\begin{array}{l}0.59 \pm 0.13 \\
0.90 \pm 0.18 \\
0.61 \pm 0.07\end{array}$ & $\begin{array}{l}<0.001 \\
<0.001 \\
<0.001\end{array}$ & $\begin{array}{l}<0.001 \\
<0.001 \\
<0.001\end{array}$ & $\begin{array}{l}0.0445 \\
<0.001 \\
<0.001\end{array}$ & $\begin{array}{l}0.1776 \\
<0.001 \\
<0.001\end{array}$ & \\
\hline
\end{tabular}

Notes: aVT = delivered tidal volume measured by the ASL 5000 lung model; sVT = ventilator set tidal volume of $30 \mathrm{~mL}$.

Abbreviations: DCV, dual-controlled ventilation; VCV, volume-controlled ventilation.

discrepancies further emphasize the need for careful evaluation of each study with consideration of the ventilator and anesthesia machine used given the potential for variation from manufacturer to manufacturer. Additionally, findings may vary based on whether the studies are performed in the healthy state or in the setting of lung injury. These factors must also be carefully considered in clinical practice. 
A

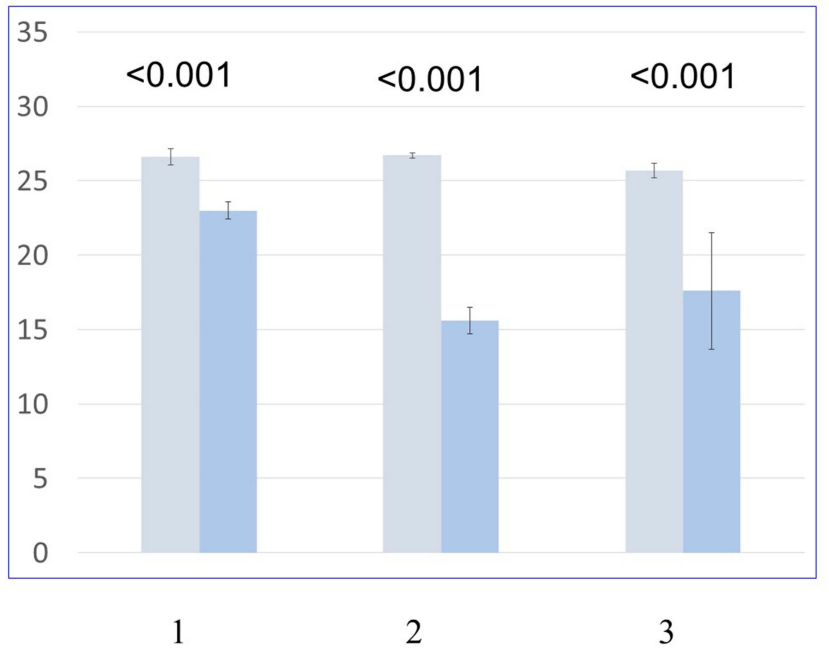

B

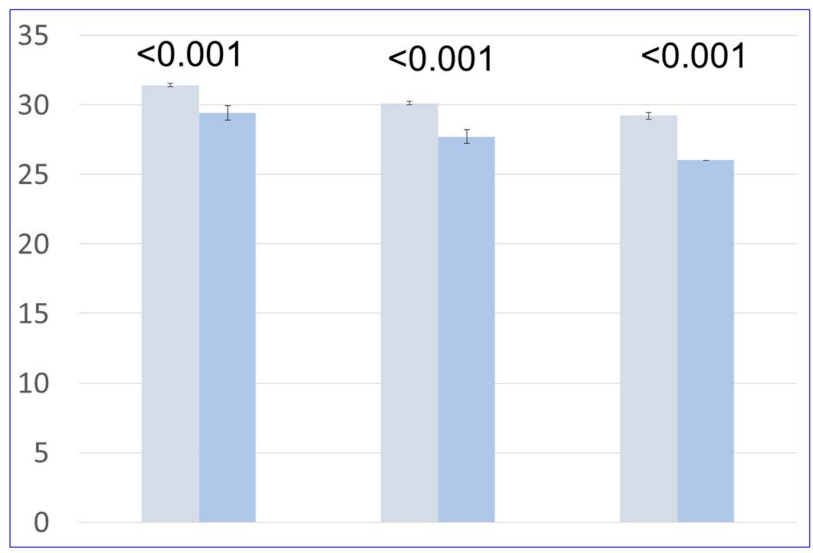

\section{C}

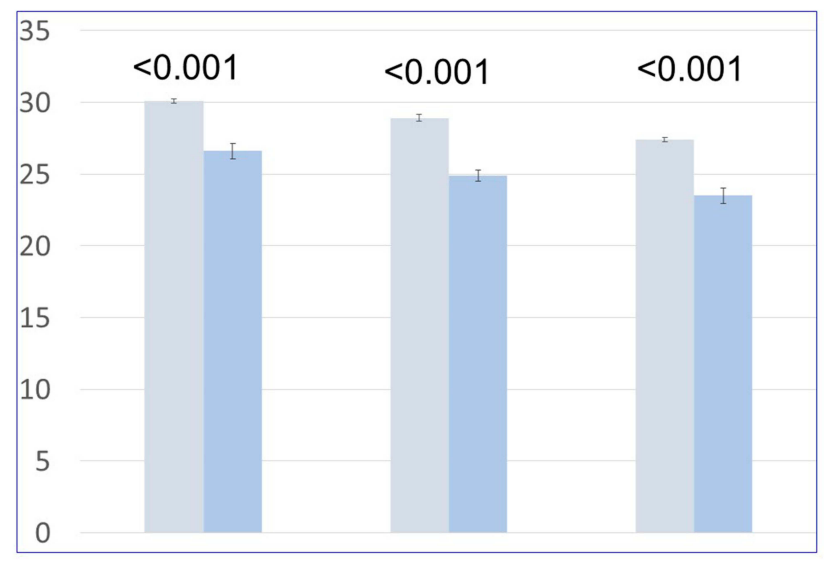

D 1

2

3

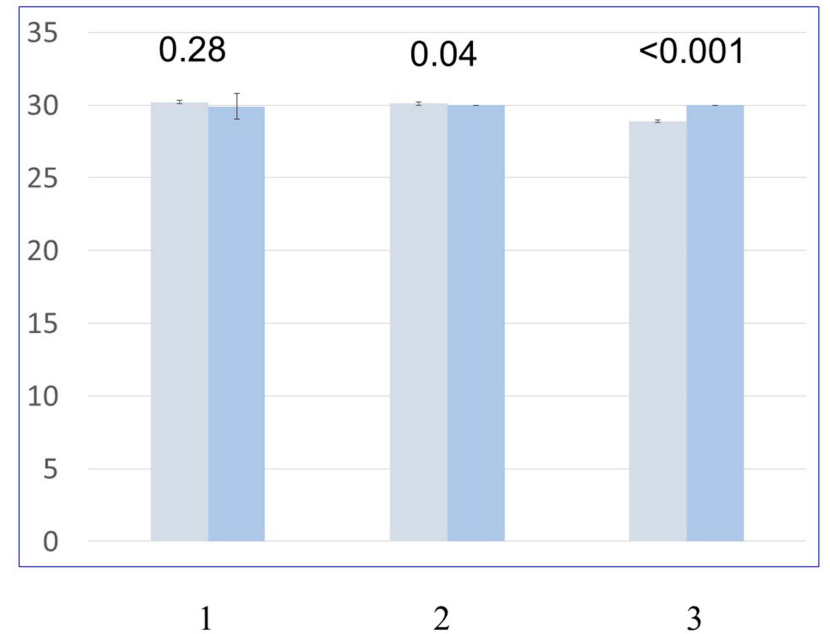

E

2

mVT
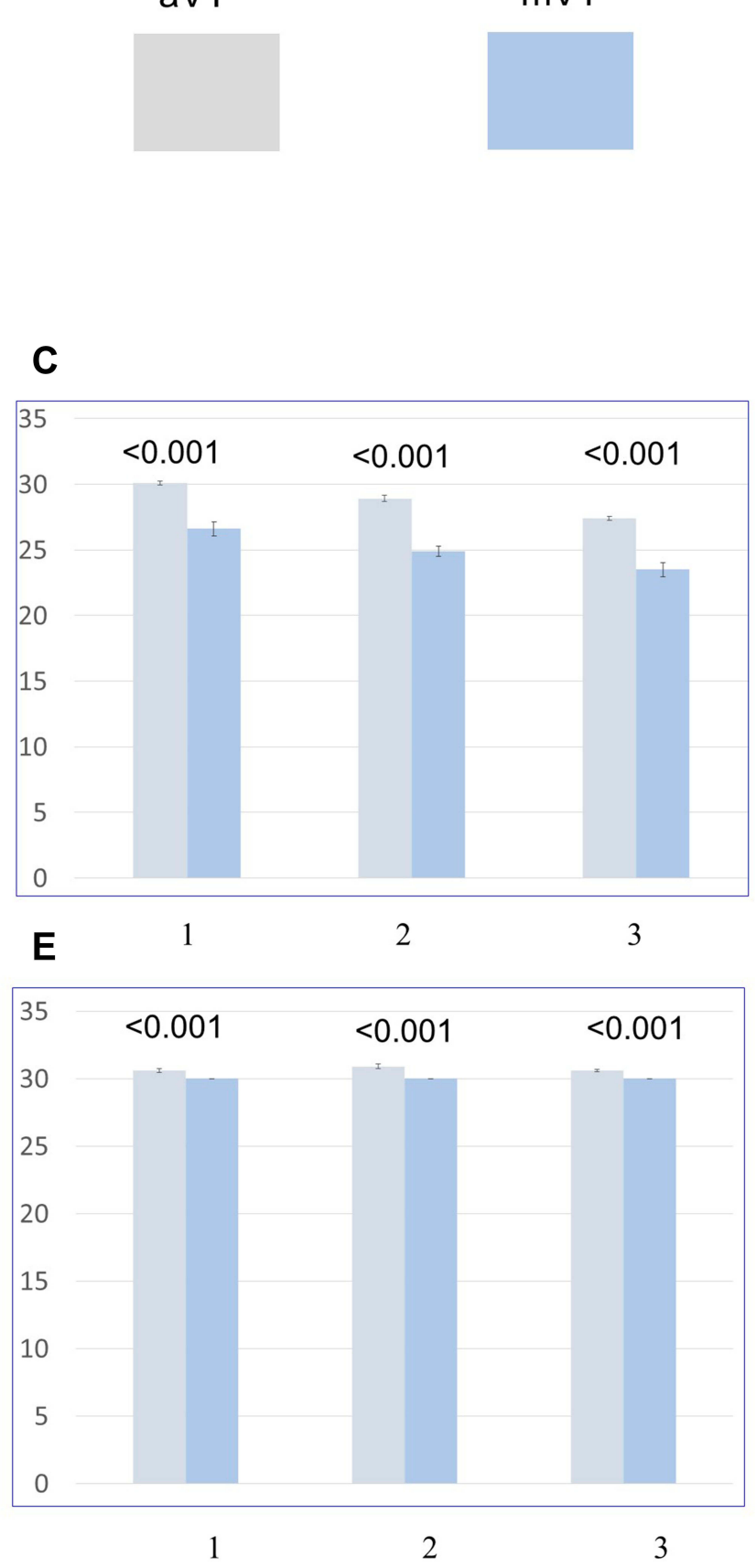

Figure 2 Actual delivered tidal volume measured by the ASL 5000 (aVT) and measured or ventilator displayed tidal volume (mVT) in each setting. Mean value and standard deviation (error bar) are shown. P values are shown above the bar graph. (A) Fabius GS, VCV; (B) Servo-i, VCV; (C) Servo-i, DCV; (D) Infinity V 500, VCV; and (E) Infinity $\checkmark 500$, DCV. aVT = delivered tidal volume measured by the ASL 5000 lung model; mVT = ventilator displayed or measured tidal volume.Abbreviations: DCV, dualcontrolled ventilation; VCV, volume-controlled ventilation. 
The pre-use self-test of the circuit may also affect the dissociation between mVT and aVT if the circuit is not fully expanded for the self-test. Using four anesthesia machines and a test lung, Glenski et al reported that performing a pre-use self-test on a non-expanded pediatric circuit leads to a falsely elevated $\mathrm{mVT}^{8}$. To avoid this situation, pre-use self-test was performed on an expanded circuit in our study.

Patient lung size, lung compliance, and airway resistance are also important factors that may lead to a discrepancy between sVT, mVT, and aVT. Although $\mathrm{mVT}$ by the Infinity V 500 was precise, mVT by the Fabius GS was highly different from aVT, especially in the injured lung model. Using ASL 5000 and several mechanical ventilators including PB 840, Servo 300, and Evita 4 NeoFlow, Toyama et al compared $\mathrm{mVT}$ and aVT in both normal and injured lung model using the following parameters in the VCV mode: VT $30 \mathrm{~mL}$, respiratory rate 20 breaths/minutes, inspiratory time 0.4 seconds, endinspiratory pause 0.1 seconds, and PEEP $5 \mathrm{cmH} 2 \mathrm{O} .^{9}$ They reported that aVT by the Evita 4 was approximately equal to the sVT both in normal lung model and in the injured lung model. However, both the PB 840 and Servo 300 ventilators could not deliver a clinically acceptable aVT in the injured lung model. Although this study used the ASL 5000, the study design was different from our study because they used a pneumotachometer to evaluate aVT. Despite these factors, the results were consistent with our study.

Several types of flowmeters are used in commercial mechanical ventilators, orifice meters, ultrasonic flowmeters, hot wire or hot film anemometers, Fleisch and screen (or Lilly) pneumotachometers. Fabius GS and Infinity V 500 use hot wire sensors. Servo-i uses an ultrasonic sensor. Hot wire sensors have been shown to be more accurate than ultrasonic sensors. ${ }^{10}$ Although this did not explain the difference between Fabius GS and Infinity $\mathrm{V} 500$, it may be partly responsible for the improved accuracy of the Infinity V 500 compared to the Servo-i ICU ventilator.

Given our results and previous studies, physicians need to consider the following in clinical situations. There may be significant variations in the efficacy of mechanical ventilation based on the type of ventilator used. The pre-use self-test should be performed only with the circuit expanded to its anticipated length. ${ }^{8}$ In the current study, the mVT recorded by the anesthesia machine ventilator was not reliable in a simulated newborn patient and this discrepancy was greater in the setting of lung injury. Regardless of the setting used, as sVT is increased to increased aVT or mVT, peak and plateau inflating pressure should be monitored to avoid volutrauma and barotrauma. Flow-volume loops when available may show a beak sign indicative of lung over-distention. In the setting of acute lung injury, depending on the anesthesia machine ventilator that is available, use of an ICU ventilator may be needed to ensure accurate tidal volumes if a volume-controlled mode is chosen. Alternatively, a pneumotachometer placed between the Y-piece and the ETT may be needed to accurately measure aVT and allow for adjustments of sVT.

In lung simulation studies, given the number of measurements made, the standard deviation may artificially low. Therefore, clinically significant differences are more important than statistically significant differences. This study is a lung simulator study, performed without $\mathrm{CO} 2$ monitoring and use of a heat moist exchanger which may impact the results. Although we used the ASL 5000 to simulate a neonatal lung and evaluate aVT, the technology differs somewhat from previous studies. However, the measurement of VT by the ASL 5000 is performed by displacement of a syringe and as such should eliminate the inaccuracies which may occur with use of a pneumotachometer that integrates flow and time to calculate VT. Ventilator design is constantly improving and results will likely vary with newer version anesthesia machines. Finally, the results of the study may be influenced by the actual ventilator settings used, type of ETT used (cuffed or uncuffed) and the resultant air leak, the use of neuromuscular blocking agents, as well as the respiratory mode (spontaneous, assisted, or controlled). The current study focused on controlled ventilation without simulation of spontaneous ventilation use a cuffed ETT to seal the airway.

In conclusion, the discrepancy between sVT, aVT, and mVT using two modern ICU mechanical ventilators was clinically acceptable in the absence of lung injury. The discrepancies increased with simulated lung injury, being greater with the Servo-i ventilator. However, the differences noted when using the anesthesia machine were not clinically acceptable, especially in the injured neonatal lung model.

\section{Acknowledgment}

The authors would like to thank clinical engineering team in Yokohama City University Hospital for technical support. The results of this paper were presented at the American Society of Anesthesiologists annual meeting 
2019 in Orlando, USA as a poster presentation talk with interim findings by Yoshikazu Yamaguchi. The poster's abstract was published in the ASA website http://www. asaabstracts.com/strands/asaabstracts/abstractList.htm? year $=2019 \&$ index $=16$

\section{Author Contributions}

All authors made substantial contributions to conception and design, acquisition of data, or analysis and interpretation of data; took part in drafting the article or revising it critically for important intellectual content; gave final approval of the version to be published; and agree to be accountable for all aspects of the work.

\section{Funding}

There is no funding to report.

\section{Disclosure}

The authors declare no conflict of interest.

\section{References}

1. Wheeler KI, Klingenberg C, Morley CJ, Davis PG. Volume-targeted versus pressure-limited ventilation for preterm infants: a systematic review and meta-analysis. Neonatology. 2011;100(3):219-227. doi:10. $1159 / 000326080$
2. Bachiller PR, McDonough JM, Feldman JM. Do new anesthesia ventilators deliver small tidal volumes accurately during volume-controlled ventilation? Anesth Analg. 2008;106(5):1392-1400, table of contents. doi:10.1213/ane.0b013e31816a68c6

3. Marchese AD, Chipman D, de la Oliva P, Kacmarek RM. Adult ICU ventilators to provide neonatal ventilation: a lung simulator study. Intensive Care Med. 2009;35(4):631-638. doi:10.1007/s00134-0081332-0

4. Castle RA, Dunne CJ, Mok Q, Wade AM, Stocks J. Accuracy of displayed values of tidal volume in the pediatric intensive care unit. Crit Care Med. 2002;30(11):2566-2574. doi:10.1097/00003246200211000-00027

5. Cannon ML, Cornell J, Tripp-Hamel DS, et al. Tidal volumes for ventilated infants should be determined with a pneumotachometer placed at the endotracheal tube. Am J Respir Crit Care Med. 2000;162(6):2109-2112. doi:10.1164/ajrccm.162.6.9906112

6. Neve V, Leclerc F, Noizet O, et al. Influence of respiratory system impedance on volume and pressure delivered at the $\mathrm{Y}$ piece in ventilated infants. Pediatr Crit Care Med. 2003;4(4):418-425. doi:10.1097/01.PCC.0000090289.98377.15

7. Heulitt MJ, Thurman TL, Holt SJ, Jo CH, Simpson P. Reliability of displayed tidal volume in infants and children during dual-controlled ventilation. Pediatr Crit Care Med. 2009;10(6):661-667. doi:10.1097/PCC.0b013e3181bb2b2b

8. Glenski TA, Diehl C, Clopton RG, Friesen RH, Lerman J. Breathing circuit compliance and accuracy of displayed tidal volume during pressure-controlled ventilation of infants: a quality improvement project. Paediatr Anaesth. 2017;27(9):935-941. doi:10.1111/pan.13164

9. Toyama H, Endo Y, Ejima Y, Matsubara M, Kurosawa S. Comparison of actual tidal volume in neonatal lung model volume control ventilation using three ventilators. Anaesth Intensive Care. 2011;39(4):599-606.

10. Schena E, Massaroni C, Saccomandi P, Cecchini S. Flow measurement in mechanical ventilation: a review. Med Eng Phys. 2015;37 (3):257-264. doi:10.1016/j.medengphy.2015.01.010
Medical Devices: Evidence and Research

\section{Publish your work in this journal}

Medical Devices: Evidence and Research is an international, peerreviewed, open access journal that focuses on the evidence, technology, research, and expert opinion supporting the use and application of medical devices in the diagnosis, monitoring, treatment and management of clinical conditions and physiological processes. The identification of novel devices and optimal use of existing devices which will lead to improved clinical outcomes and more effective patient management and safety is a key feature of the journal. The manuscript management system is completely online and includes a very quick and fair peer-review system. Visit http:// www.dovepress.com/testimonials.php to read real quotes from published authors. 